\title{
Sir
}

Benjamin Collins Brodie increased our knowledge of diseases of joints by his prolonged studies of their clinical and pathological manifestations.

He was born in 1783, the fourth of six children of the Rector of Winterslow in Wiltshire, the Reverend Peter Bellinger Brodie, M.A., who was educated at Charterhouse and Worcester College, Oxford, and of Sarah, daughter of Benjamin Collins, banker and printer of Milford near Salisbury. The Brodies derived from a clan of Morayshire; an Alexander Brodie of Brodie was Lord of Session in 1649 and his Jacobite descendant, also named Alexander, migrated to London in the earlier part of the eighteenth century. He married Margaret, daughter of another Stuart follower, Dr Samuel Shaw the physician. Two of their grandchildren, Lord Denman and Sir Benjamin Brodie, rose to eminence in law and medicine, one became Lord Chief Justice and the other President of the Royal College of Surgeons.

The Reverend Peter Brodie was unable to send his children to public school and university; he undertook their education himself. They certainly received a thorough grounding in the classics and mathematics, of which Benjamin gave ample proof later in life. Part of parental tutoring was the inculcation of industrious habits; the son who became surgeon of St George's was noted at the hospital for his ceaseless industry. But it was not all work, there was play-acting, in which young Denman joined, and the pastimes of the countryside. In 1798 there was a diversion of more serious intent. In that year Napoleon had an army at Boulogne watching a favourable moment for the invasion of Britain. There was considerable alarm in England, of which the still standing defensive Martello Towers of the south coast are a symbol. Brodie and his brothers raised a company of volunteers under a commission signed by George III whereby William was appointed Captain and "Our trusty and well-beloved Benjamin Collins Brodie, gent, Ensign in the company."

In 180I, at the age of eighteen years, Brodie came to London to study medicine, not that he felt any strong attraction towards the healing art at that time; he had family. connections with distinguished physicians like Dr Matthew Baillie and Dr Denman. He joined Abernethy's school of anatomy; here he met William Lawrence, afterwards surgeon to St Bartholomew's Hospital, with whom he formed a lifelong friendship. The following vear he attended the lectures of James Wilson at the Hunterian School of Anatomy in Great Windmill street and worked hard at dissection. After spending nearly two years at these studies he entered St George's Hospital as a pupil of Everard Home in 1803. Early the following vear his father died, leaving Mrs Brodie in straitened circumstances, dependent on a fixed income in days of high prices, war taxation and depreciation of paper currency; an economy strangely descriptive of England a hundred and fifty years on. But with austere living, saving and some sacrifice of capital she just managed to keep up supplies to her sons in mid-career.

In May 180; Brodie became house surgeon, a post which he held for six months, when he resigned on appointment as lecturer in anatomy at the Windmill Street School. About the same time he accepted a proposal from Everard Home to become his assistant in private practice and in his researches on comparative anatomy at the Royal College of Surgeons. These appointments were of supreme importance to Brodie for, as he remarked, "These occupations afforded me the means of learning much as to my profession which cannot be learnt in a hospital; and further by initiating me in the study of anatomy and physiology generally, without limiting my views merely to that which is required for surgical practice they led me to scientific inquiries." At the College of Surgeons he was fortunate in having 


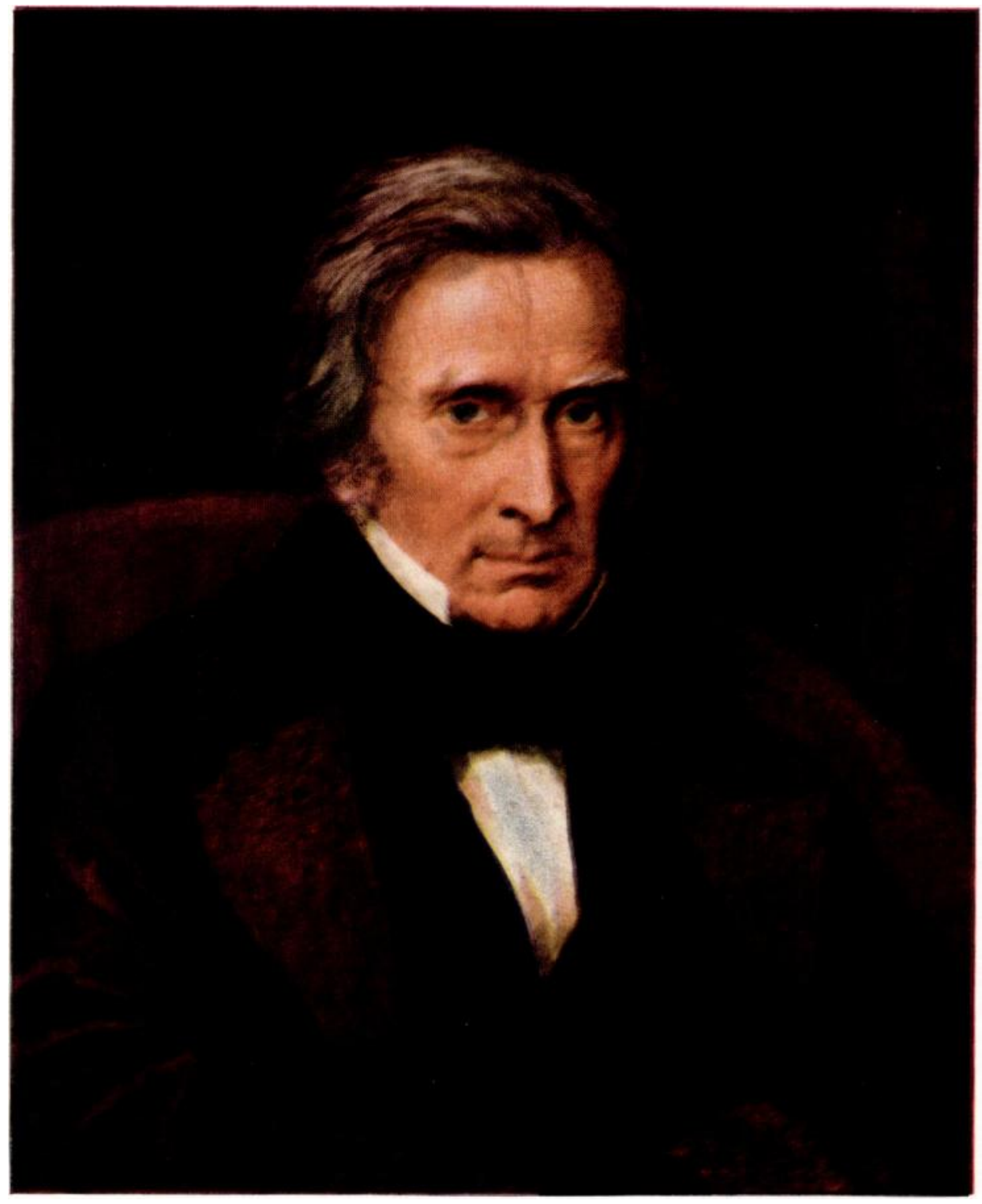

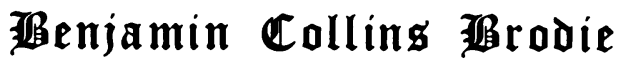

$1783=1862$ 
the help and guidance of Clift, the Conservator of the Museum, who in his youth had lived in John Hunter's home and was trained by him. Clift had an intimate knowledge of every specimen and manuscript such as no one else had.

In 1808 Brodie was appointed assistant surgeon to St George's Hospital, being attached to Everard Home; owing to the absence of Gunning, another surgeon, in the Peninsular War, Brodie and Robert Keate shared his duties. Brodie was at the hospital every day; he introduced clinical clerks on the surgical side who were taught the duty of accurate case recording; regular teaching was imparted in the wards and he delivered a course of clinical lectures on surgery, the first of their kind in a London hospital. The same year he joined. James Wilson in lecturing on surgery at the Windmill Street School.

His researches at the Royal College of Surgeons and his association with Sir Everard Home and Clift brought him into intimate contact with Sir Joseph Banks, Sir Humphry Davy, Wollaston and other scientists. In $\mathbf{1 8 1 0}$ he was elected a Fellow of the Royal Society and the same year delivered the Croonian Lecture " On the Influence of the Brain on the action of the Heart, and the Generation of Animal Heat." He also communicated a paper on " The effects produced by certain Vegetable Poisons." In 1811 he was awarded the Copley Medal of the Society for his physiological researches.

In 1816 he married a daughter of Serjeant Sellon who had been a barrister of a good deal of repute and the author of Sellon's Practice, a work much valued by the legal profession. They lived first at 22 Sackville Street, but three years later moved to a larger house in Savile Row. There were two sons and a daughter of the marriage; the elder son became a Fellow of the Royal Society and Wayneflete Professor of Chemistry at Oxford, after a notable career at Harrow and Balliol. The younger son became Vicar of East Meon.

In 1819 Brodie succeeded Lawrence as Professor of Comparative Anatomy and Physiology at the Royal College of Surgeons. He lectured on the functions of the organs of respiration, circulation and digestion, and on the nervous system. In practical surgery he was interested above everything else in diseases of joints, to which his attention was first directed when as house surgeon he dissected a specimen consisting of a pathological dislocation of the hip. He realised that when disease appeared in a joint much confusion often prevailed as to its nature. The pathology of joint disease had been neglected; there was great need of investigation, particularly of the early stage of disease. With this in mind he wrote: "I availed myself of every opportunity which occurred of making such examinations. In particular I was anxious to do this when the morbid changes were still in an early stage, and where I had the opportunity of noting the symptoms by which the incipient disease was indicated; and the knowledge thus acquired became the basis of my future observations." From the time he became assistant surgeon he kept a record of almost every patient with articular disease under his care and dissected any joint with incipient disease in post-mortem examinations of patients who had died from other causes. Brodie's researches on joint disease occupied the greater part of his professional life. In 1818 he published his great treatise on Pathological and Surgical Observations on the Diseases of the Joints; it went through five editions, the last in 1850. With the appearance of this work his advancement was rapid and it secured him an international reputation. It was the first serious attempt to separate the various conditions grouped together as " white swelling." He drew attention to the hysterical joint, then prevalent among young women of the more favoured class, due to mistaken ideas of phrsical exercise and education. He had considerable success with spinal caries by his enforced and prolonged recumbency, preferably at the seaside. He was against any attempt at correction of the kyphos, for he believed that the collapsed vertebrae provided for a more certain anyklosis. He wrote: "Without such undue interference on the part of the surgeon, the carious surface of the vertebra above will always come in contact with that of the vertebra below; and it is to the union which takes place under these circumstances, at first by soft substance, and afterwards by bony matter, and to this alone, that we are to look for the

VOL. $36 \mathrm{~B}$, No. 3, AUgust 1954 
patient's recovery. Whatever disturbs this process (and any attempt to straighten the spine cannot fail to do so) must therefore be carefully avoided."

He speaks of paraplegia as a complication of spinal caries but was able to report the good result of prolonged recumbency as follows: "Paralysis of the muscles below the seat of the disease must always be regarded as an unfavourable symptom. Yet in many instances, after being for some time in the recumbent posture, the power of the will over the muscles begins to be restored; and I have known children, in whom the muscles of the lcwer limbs had been completely useless, after the lapse of three or four years, to be able to walk and run and jump as well as if they had never laboured under any kind of disease."

In 1822 Brodie became surgeon to St George's Hospital; for the next eighteen years he was heavily engaged in his hospital and private practice; he lectured a great deal and continued with his physiological researches. In 1821 he attended King George IV when Sir Astley Cooper removed a sebaceous cyst. In 1828 when Sir Astley became Serjeant Surgeon Brodie succeeded him as Surgeon to His Majesty. He was in daily attendance at Windsor during the King's last illness two years later. In 1832 he became Serjeant Surgeon to King William If and afterwards to Queen Victoria. In $\mathbf{1 8 3 4}$ he was made a baronet; the same year he was admitted a member of the Council of the Royal College of Surgeons and a member of the Court of Examiners. Three years later he delivered the Hunterian Oration; he was elected President of the Royal College of Surgeons in 1844. He resigned from the staff of St George's Hospital in 1840, at the age of fifty-seven. His departure was made the occasion for the appreciation and gratitude of the profession, for his eminent services to surgery, by the presentation of the large "Brodie Medal " at a public dinner. On the obverse side is a bust of Sir Benjamin and on the reverse a female figure, emblematical of medicine, in a kneeling attitude trimming the Hygeian lamp. Lady Brodie wrote to her son saying, " The likeness is perfect, and I cannot find a fault with it." The original medal was presented to the Royal College of Surgeons by the present baronet in 1953; it was the work of Wyon of the Royal Mint.

After thirty two years of strenuous effort at the hospital he said that, after his resignation, he never passed St George's without a sense of regret that his work there was over. To lessen this feeling he delivered a short course of lectures to the students each winter session, " generally selecting for his subject some one class of disease, and giving a more detailed history of his own experience than was possible in an ordinary course of surgical lectures." Two diseases which have perpetuated his name, Brodie's abscess and Brodie's tumour, were the subjects of lectures delivered in these courses.

\section{BRODIE'S ABSCESS}

The lecture on abscess of the tibia was delivered in the theatre of St George's Hospital on November 19, 1845. It is reported in the London Medical Gazette for 1845 . He said: "In the year 1824 I was consulted by a young man, 24 years of age, under the following circumstances: There was a considerable enlargement of the lower end of the tibia, but the ankle joint admitted of every motion and was apparently sound. The skin was thin, tense, and closely adherent to the periosteum. There was constant pain in the part, generally of a moderate character, but every now and then it became excruciating, keeping the patient awake at night and confining him to the house for many successive days. It made his life miserable and his nervous system irritable: one effect of which was that it spoiled his temper and thus produced another set of symptoms in addition to those which were the direct consequences of the local malady. The disease had been going on for twelve years. He had consulted a number of surgeons respecting it, and had used a vast variety of remedies, but had never derived benefit from anything that was done. Instead of getting better, he every year became so much worse. I tried some remedies without any advantage, and at last recommended that he should lose the limb. Mr Travers saw him with me and agreed in this opinion. Amputation was performed, and the amputated tibia is now on the table. You will 
see how much the lower end of it is enlarged, and that the surface of it presents marks of great vascularity. The bone in the preparation is divided longitudinally, and just above the articulating surface there is a cavity as large as a small chestnut. This cavity was filled with dark-coloured pus. The inner surface of it is smooth. The bone immediately surrounding it is harder than natural. The examination of the limb explained all the symptoms: there was an abscess of the tibia, stretching the bone in which it was formed, or rather, if I may use the expression, trying to stretch it, and thus causing the violent pain which the patient suffered. On observing these appearances, I could not help saying, that if we had known the real state of the disease the limb might have been saved. A trephine would have made an opening in the tibia, and have let out the matter. It would have been merely applying the treatment here that we adopt in the case of abscess elsewhere. You open a painful abscess of the arm with a lancet: you cannot open an abscess of the bone with a lancet, but you may do so with a trephine.

"About two years after the occurrence of this case I was consulted by another patient, 23 years of age, who had an enlargement of the upper end of the tibia extending to some distance below the knee. He suffered a great deal of pain, the part was very tender, and there were all the symptoms of chronic periostitis. I made an incision over the part, dividing everything down to the bone, and found the periosteum very much thickened. There was a new deposit of bone under the periosteum, softer than the bone of original formation. This operation, as in other cases of chronic periostitis, relieved the tension and the pain, and the patient was supposed to be cured. However, about a year afterwards, in August 1827, there was a recurrence of the pain; the enlargement of the tibia, which had in some degree subsided, returned, and it continued to increase. In the enlarged tibia there was one spot a little below the knee where there was exceeding tenderness on pressure. I need not describe the symptoms more particularly; it is sufficient to say that they bore a very close resemblance to those in the last case; the only difference being that, as the disease had been of shorter duration, the pain was less severe, and that the tibia was affected in the upper instead of the lower extremity. I concluded that there must be an abscess in the centre of the bone, and applied the trephine to the tender spot. I used the common trephine made for injuries of the head, which, having a projecting rim or shoulder, would only penetrate to a certain depth. However, it enabled me to remove a piece of bone of sufficient thickness to expose the cancellous structure. Then with a chisel I removed some more of the bone. Presently there was a flow of pus in such quantity as completely to fill the opening made by the trephine and the chisel. It seemed as if the bone had been to a certain extent kept on the stretch by the abscess and that, as soon as an opening was made into it, it contracted and forced up the matter. The patient was well from that time; the would healing very favourably, and he has never had any return of the disease ... When the tibia is enlarged from a deposit of bone externally - when there is excessive pain, such as may be supposed to depend on extreme tension, the pain being aggravated at intervals, and these symptoms continue and become aggravated, not yielding to medicines or other treatment that may be had recourse to-then you may reasonably suspect the existence of abscess in the centre of the bone. You are not to suppose that there is no abscess because the pain is not constant; on the contrary, it very often comes on only at intervals, and in one of the cases which I have related there was, as I then mentioned, an actual intermission of seven or eight months. After the disease has lasted a certain number of years, indeed, the pain never entirely subsides, but still it varies, and there are periods of abatement and of exacerbation." He gave details of patients with similar signs successfully treated by bone trephining. He recommended the use of a small-sized trephine without rim or shoulder.

\section{BRODIE'S TUMOUR}

The lectures dealing with tumour of the breast are reported in the Medical Times for 1844 . " In the present lecture I shall make some observations on the diseases of the breast, no very

rol. 36 B, No. 3, AUgUST 1954 
clear description having been given of them, although of common occurrence. The disease to which I shall particularly refer to-day is one of considerable interest; especially so, because it is quite different from carcinoma with which it has been frequently confounded. It is not met with in hospital practice, but very often shews itself in private life, and unless I had had the advantage of seeing a large number of private patients, I should not have been able to make out its symptoms and history, as I believe I now can ... A lady consulted me who had one of these tumours in her breast, about the size of a walnut; I punctured it with a needle first and, finding it contained serum, I laid it open with a lancet; a large quantity of fluid escaped. I then dressed it with lint to the bottom, meaning to bring on inflammation: a good deal of suppuration followed, and the wound was two months before it healed, and then the disease was apparently quite eradicated. About a year after this the patient came to me again, and I found, where I had opened the cyst, a fungous tumour as large as the cyst I had previously opened. I recommended her to have the breast amputated; the operation was performed, and we found it to be entirely made up of cysts containing fluid matter, and one of a large size as represented in the drawing on the table. From the inner surface of this crist there projected a solid tumour, which appeared to be made up of numerous folds giving it a plicated appearance, covered by membranes continuous with that lining the cyst; and when cut into, it looked like very slightly organized fibrine . . . The disease, as I have said before, is not cancerous; but still it should be removed; because if allowed to remain, the local irritation will destroy the life of the patient; and if removed, it will not return. If you operate at all you must remove the whole of the breast, for it is no use taking away small portions. It is better to perform the operation whilst the tumour is small; nevertheless you are not to be deterred by its magnitude, because it is not in this disease as in carcinoma; there is, in fact, no danger: and I have seen a great many cases where the operation has been performed and the disease has never returned ... I have given no name to this affection because I think it is an error of modern times to be continually giving new names to diseases, but if it must have a name, I think it should be called sero-cystic tumour."

\section{INTEREST IN MEDIGAL EDUGATION}

Next to his interest in diseases of joints Brodie gave a good deal of attention to maladies of the urinary system. In pre-antiseptic days lithotomy was not without serious risks: to avoid them Civiale introduced lithotrity. Brodie was quick to appreciate the greater safety of this procedure and took a leading part in England in advocating lithotrity in place of lithotomy.

Relieved of hospital duties Brodie was able to spend more of his time at Broome Park, an estate at Betchworth, Surrey, which he purchased in 1837. Furthermore he gave more attention to medical education and reform, both of which had always interested him. In 1843 he played a prominent part in extending the constitution of the Royal College of Surgeons, whereby a new order of members under the title of Fellows, qualified by a higher standard of examination, was to be established. The object of this institution was " to insure the introduction into the profession of a certain number of young men who may be qualified to maintain its scientific character, and will be fully equal to its higher duties as hospital surgeons, teachers and improvers of physiological, pathological, and surgical science afterwards." A new charter enabling the College to carry out this reform was granted by the Crown in 1843 . By this instrument all power of election was vested in the Fellows; retention of office for life by examiners and members of Council was abolished; the offices of president and vice-president were restricted to members of the Court of Examiners.

With the passing of the Medical Act in 1858 the General Medical Council of Medical Education and Registration became established. The Council was authorised to require from licensing bodies information as to courses of study and examinations and to visit and inspect examinations. A register was to be established of persons holding a diploma or licence from 
a licensing body after examination. Brodie was chosen to be the first president of this council. A few days later he reached the climax of his career when he was elected President of the Royal Society, a position he filled with dignity and distinction. It was particularly gratifying to him that his heir occupied the chair of the Chemical Society at the same time and that he had previously been awarded the Royal Medal of the Royal Society.

In his last years Brodie wrote a short work on metaphysics entitled Psychological Inquiries. It bears the influence of Berkeley and is cast in the form of a dialogue; it first appeared in 18.54 and passed through four editions. He treats the question of the existence and creative energy of God as settled and teaches that mind and matter are different in their nature, so that mental phenomena cannot be regarded as the product of material forces. He attributes great importance to the imagination and its training by education; the possession of this great faculty distinguishes man from the lower creatures; men live in the world of the imagination as much and as truly as they do in the world of sense. All philosophies rest on certain assumptions and one such for Brodie was " the existence of one's own mind is the only thing of which one has any positive and actual knowledge." Regarding personal conduct he dwells on the necessity for " another quality for which he can find no other English name than that of humility, though that does not exactly express the meaning, that quality which leads a man to look unto himself, to find out his own deficiencies and endeavour to correct them, to doubt his own observations until they are carefully verified." This in effect is an echo of Pauline teaching, "For I say, through the grace given unto me, to every man that is among you, not to think of himself more highly than he ought to think."

Brodie's personal appearance was striking, though not perhaps handsome; his frame was slight and small but he had consuming energy. In private life he was known for his playful humour and fund of anecdote. As a lecturer " none who heard him can forget the graphic yet artless manner in which, sitting at his ease, he used to describe minutely what he himself had seen and done under circumstances of difficulty, and what under like circumstances he would again do or would avoid." When Astley Cooper retired Brodie became his natural successor as the leading surgeon in England, added to which he had more intimate contact with leaders of science and literature. He was a man of great erudition; a rare combination of surgeon, scientist and philosopher. He had a Hunterian attitude towards surgery in that he regarded scientific research to be the handmaid of practice. In particular he clarified our knowledge of joint disease. He made a lasting contribution towards medical education whereby preliminary instruction in the arts and professional training were greatly improved. By his advocacy of reform of the Royal College of Surgeons he helped to raise its status as a governing body and enhanced the quality of those whom it approved to practice surgery.

For the last few years of his life he suffered from double cataract, for the relief of which Sir William Bowman operated. In July 1862 he began to complain of pain in his right shoulder, caused by malignant disease; he died on October 21 . Twenty-eight years before he had fallen from a pony and dislocated this joint. Lady Brodie had passed away the previous year. ARTHUR ROCYN JONES.

\section{REFERENCES}

British Journal of Surgery (1918): Sir Benjamin Collins Brodie, Bart. 6, 157.

IBritish Journal of Strgery (1922): Eponyms. III. Brodie's Tumour, and Brodie's Abscess 9, 334.

Brodie, Sir Benjamin C. (1844): A Course of Clinical Lectures on Some Important Points of Surgery. Lectures 8 and 9. Medical Times, 10, 163, 191.

Brodie, Sir Benjamin C. (1845): Lecture on Abscess of the Tibia. London Medical (razette, N.S. 1, 1,399. Brodie, Sir Benjamin C. (1850): Pathological and Surgical Observations on the Diseases of the Joints. Fifth edition. London: Longman, Brown, Green, and Longmans.

Bronie, Sir Benjamin Collins (1865): The Works of Sir Benjamin Collins Brodie arranged by Charles Hawkins. Three Volumes. London: Longman, Green, Longman, Roberts, \& Green.

Holmes, Timothy (1898): Sir Benjamin Collins Brodie. London: T. Fisher Unwin.

We are grateful to Capt. Sir Benjamin Collins Brodie, 4th Baronet, for permission to reproduce the portrait of his great-grandfather painted by G. F. Watts.]

vol. $36 \mathrm{~B}$, No. 3, ACgest 1954 